Article

\title{
Resistance and Virulence Features of Bacteroides spp. Isolated from Abdominal Infections in Romanian Patients
}

\author{
Gabriela Roxana Pricop ${ }^{1}\left(\mathbb{D}\right.$, Irina Gheorghe ${ }^{1,2, *}$, Gratiela Gradisteanu Pircalabioru ${ }^{2, *} \mathbb{(}$, \\ Violeta Cristea ${ }^{1}$, Marcela Popa ${ }^{2}$, Luminita Marutescu ${ }^{1,2}$, Mariana Carmen Chifiriuc ${ }^{1,2,3} \mathbb{1}$, \\ Grigore Mihaescu ${ }^{1}$ and Eugenia Bezirtzoglou ${ }^{4}$ (D) \\ 1 Faculty of Biology, Department of Microbiology and Immunology, University of Bucharest, \\ 060101 Bucharest, Romania; priroxana@yahoo.com (G.R.P.); dr.violetacristea@gmail.com (V.C.); \\ lumi.marutescu@gmail.com (L.M.); carmen.chifiriuc@gmail.com (M.C.C.); \\ mihaescuapelevii@gmail.com (G.M.) \\ 2 Department of Earth, Environment and Life Sciences, The Research Institute of the University of Bucharest (ICUB), \\ University of Bucharest, 050095 Bucharest, Romania; bmarcelica@yahoo.com \\ 3 Academy of Romanian Scientists, 050045 Bucharest, Romania \\ 4 Laboratory of Microbiology, Biotechnology and Hygiene, Department of Food Science and Technology, \\ Faculty of Agricultural Development, Democritus University of Thrace, 67100 Orestiada, Greece; \\ empezirt@yahoo.gr \\ * Correspondence: iryna_84@yahoo.com (I.G.); gratiela87@gmail.com (G.G.P.)
}

Received: 22 October 2020; Accepted: 10 November 2020; Published: 12 November 2020

\begin{abstract}
Anaerobic bacteria are predominant residents of the normal microbiota of the skin and mucous membranes but are also known to be associated with a number of human infections including peritonitis, appendicitis, abscesses, ulcers and wound infections. Herein, we investigate the antibiotic resistance profiles as well as the genetic support of antibiotic resistance and virulence determinants of anaerobic bacteria isolated from intra-abdominal infections. The study was performed on 198 Romanian patients from which different clinical samples were taken intra-operatory and sent for microbiological analyses. From the total number of isolated strains, a subset of 75 Bacteroides spp. were selected and further investigated for antibiotic resistance and virulence features, at phenotypic and genetic level. Our results obtained through the analysis of a significant number of Bacteroides strains could shed light on the virulence potential and mechanisms by which anaerobic bacteria can cause endogenous infections.
\end{abstract}

Keywords: anaerobe; infection; Bacteroides; antibiotic resistance

\section{Introduction}

Anaerobic bacteria are predominant residents of the normal microbiota of the skin and mucous membranes in humans [1], but are also involved in a wide plethora of infections including peritonitis, appendicitis, odontogenic infections, cellulitis, abscesses, ulcers and wound infections [2].

Recent studies have shown a tremendous increase in the association of anaerobic bacteria belonging to Bacteroides, Fusobacterium, Peptococcus, Propionibacterium, Bifidobacterium, Lactobacillus, Clostridium, Actinomyces, Finegoldia, Veillonella, Prevotella, Fusobacterium, Campylobacter, Porphyromonas and Peptostreptococcus genera with clinical infections [3]. However, due to the fastidious nature of some species, anaerobic microorganisms are often difficult to isolate from infection sites and tend to be overlooked. Importantly, the polymicrobial associations and the emergence of antimicrobial resistance often complicate the treatment course of anaerobic infections. In clinical practice, infections caused 
by anaerobic bacteria are routinely treated using antibiotics such as carbapenems, metronidazole, beta-lactam/beta-lactamase inhibitor combinations, second generation cephalosporins, quinolones and clindamycin [3-6]. However, in recent years, increasing resistance rates have been reported worldwide especially for Bacteroides isolates. Indeed, Bacteroides strains are now almost completely resistant to tetracyclines and "regular beta lactams" (penicillins and cephalosporins) and moderately resistant to for moxifloxacin, clindamycin, cefoxitin and amoxicillin/clavulanic acid. A low level of resistance was shown in case of metronidazole, carbapenems, tigecycline, and piperacillin/tazobactam. The most frequent antibiotic resistance genes described to be associated with the main antibiotic resistance phenotypes in anaerobic bacteria are: cfiA or ccrA for carbapenems, cepA for "regular beta lactams" (penicillins and cephalosporins), cfx for cefoxitin resistance, tet $Q$, tet $M$, tet36, tet $X$, tet X1 for tetracyclines nim genes (A-F), or the overexpression of $\operatorname{Rec} A$ gene, or complete disruption of electron transport chain components are responsible for metronidazole resistance, bexA for quinolones and ermB, ermF, erm $\mathrm{G}$, $\operatorname{lin} \mathrm{A}$, the efflux pumps $m s r S A$ and $m e f A$ for the MLSB (macrolide, lincosamide, streptogramin B) group of antibiotics [7].

The aim of this study was to evaluate the antimicrobial resistance profiles and the corresponding resistance genes, as well as to highlight some virulence genes, in Bacteroides strains isolated from different intra-abdominal infections in patients hospitalized for abdominal surgery in Bucharest, Romania.

\section{Results}

\subsection{Etiology of Intra-Abdominal Infections}

A total of 374 bacterial strains were isolated from 198 patients with intra-abdominal infections submitted to abdominal surgery, during January 2015-February 2016. Most samples were harvested from peritoneal fluid (32\%), appendix (15\%), bile acid (13\%), iliac pits $(12 \%)$, abdominal abscess $(8 \%)$, perforated ulcers $(7 \%)$, perihepatic abscesses $(5 \%)$, Douglas' pouch $(3 \%)$, blood culture $(2 \%)$, mesentery $(1 \%)$, pelvic abscesses $(1 \%)$ and chronic gastritis $(1 \%)$. Out of the tested clinical specimens, $171(86.3 \%)$ samples were positive for either aerobic or anaerobic bacteria or mixed growth and the rest of 27 samples were negative. Among the 171 positive culture specimens, 27 (15.7\%) showed only aerobic growth and 144 (72.7\%) showed mixed anaerobic and aerobic growth.

From the total number of the isolated strains, $46 \%$ were represented by aerobic Gram-negative bacilli with E. coli (37\%) being the most prevalent. The aerobic Gram-positive cocci, mostly comprised of Enterococcus species, represented $10 \%$ of the total number of the isolated strains (Table 1 ).

Table 1. The prevalence of the aerobic bacteria in the analyzed clinical samples.

\begin{tabular}{ccc}
\hline Group & Number & $\mathbf{\%}$ \\
\hline Gram-negative bacilli & $\mathbf{1 7 3}$ & $\mathbf{4 6}$ \\
\hline Escherichia coli & 140 & 37 \\
Klebsiella pneumoniae & 11 & 3 \\
Hafnia alvei & 13 & 3 \\
Proteus mirabilis & 6 & 2 \\
Morganella morganii & 3 & 1 \\
\hline Gram-positive cocci & $\mathbf{5 0}$ & $\mathbf{1 4}$ \\
\hline Enterococcus faecium & 24 & 7 \\
Enterococcus faecalis & 9 & 2 \\
Enterococcus durans & 5 & 1 \\
Streptococcus anginosus & 6 & 2 \\
Streptococcus constellatus & 6 & 2 \\
\hline
\end{tabular}

Among the anaerobic bacteria, the clinically significant isolates were represented by: Bacteroides spp. (20\%), Clostridium spp. (8.2\%) and Parabacteroides spp. (2\%) (Table 2). 
Table 2. The prevalence of the anaerobic bacteria in the analyzed clinical samples.

\begin{tabular}{ccc}
\hline Group & Number & $\mathbf{\%}$ \\
\hline Gram-negative rods & $\mathbf{9 4}$ & $\mathbf{2 5}$ \\
\hline B. fragilis group & 75 & 20 \\
Parabacteroides & 7 & 2 \\
Fusobacterium & 4 & 1 \\
Megamonas & 5 & 1 \\
Prevotella & 2 & 0.5 \\
Dialister & 1 & 0.2 \\
\hline Gram-positive rods & $\mathbf{4 4}$ & $\mathbf{1 2}$ \\
\hline Clostridium & 31 & 8.2 \\
Eggerthella & 2 & 0.5 \\
Cutibacterium & 11 & 2.9 \\
\hline Gram-positive cocci & $\mathbf{1 2}$ & $\mathbf{3}$ \\
\hline Finegoldia magna & 7 & 1.8 \\
Parvimonas & 5 & 1.3 \\
\hline Gram-negative cocci & $\mathbf{1}$ & $\mathbf{0 . 2}$ \\
\hline Veionella & 1 & 0.2 \\
\hline
\end{tabular}

\subsection{Antibiotic Resistance Profiles}

As Bacteroides spp. represented the most prevalent etiology of anaerobic infections, these strains were further submitted to a more detailed analysis regarding their resistance and virulence profiles. These strains were isolated from different clinical specimens (i.e., from gallbladder, perihepatic abscess, wound infection and other intra-abdominal infections). From the total of 75 Bacteroides strains belonging to different species strains, $26(35 \%)$ were B. fragilis, $16(21 \%)$ B. vulgatus, $12(16 \%)$ B. uniformis, eight $(11 \%)$ B. thetaiotaomicron, seven ( $9 \%$ ) B. ovatus, five $(7 \%)$ B. stercoris and one ( $2 \%)$ strain of B. caccae.

All Bacteroides isolates were resistant to ampicillin (MIC $2 \geq 16 \mathrm{mg} / \mathrm{mL}-$ ), penicillin (MIC 2-4 mg/L) and tetracycline [MIC $8-\geq 8 \mathrm{mg} / \mathrm{mL}$, according to Clinical Laboratory Standard Institute (CLSI) guidelines], 16 strains (21.9\%) were resistant to clindamycin (MIC $\geq 8 \mathrm{mg} / \mathrm{L}$ ), $8(10.9 \%$ ) to cefotetan (MIC $64 \geq 64 \mathrm{mg} / \mathrm{L}$ ) and only one strain (1.3\%) to cefoxitin (MIC $\geq 32 \mathrm{mg} / \mathrm{L}$ ). All strains were uniformly susceptible to metronidazole, augmentin, ampicillin-sulbactam, imipenem, meropenem, chloramphenicol and piperacillin with tazobactam. Concerning the antibiotic resistance profiles of different Bacteroides spp., $42.8 \%$ of B. ovatus strains showed resistance to cefotetan (MIC $32 \geq 64 \mathrm{mg} / \mathrm{L}$ ) followed by $37.5 \%$ of the B. thetaiotaomicron strains (MIC $8 \geq 64 \mathrm{mg} / \mathrm{L}$ ) and $6.25 \%$ of B. vulgatus isolates (MIC 4-64 mg/L) according to CLSI guidelines. The highest rate of clindamycin resistance (MIC $0.25 \geq 8 \mathrm{mg} / \mathrm{L}$ ) was harbored by B. vulgatus $(56.2 \% \mathrm{mg} / \mathrm{L})$ strains, followed by B. uniformis $(8.3 \%)$ and B. fragilis (7.6\%). The susceptibility testing results were interpreted according with CLSI and the European Committee on Antimicrobial Susceptibility Testing (EUCAST) guidelines (Tables S1 and S2).

\subsection{Distribution of Resistance Genes among Bacteroides Isolates}

Although all 75 Bacteroides spp. were resistant to ampicillin and penicillin, only 40 of them (53.3\%) harbored the cep $A$ gene and $55(72 \%)$ strains were $\beta$-lactamase producers. The cep $A$ gene was most frequently found amongst the $B$. fragilis strains; specifically, out of the 26 strains, 17 (65.3\%) harbored the cepA gene. None of the Bacteroides strains was positive for $c f x A$, although one strain of B. thetaiotaomicron was resistant to cefoxitin (MIC $\geq 32 \mathrm{mg} / \mathrm{L}$ ). It is to be mentioned that the presence of cepA gene was not correlated with the MIC value for ampicillin (AMP) and penicillin (PEN). Thus, out of the 20 Bacteroides strains with high ampicillin resistance (CMI $\geq 16 \mathrm{mg} / \mathrm{L}$ ), only 12 were positive, while from the 54 strains that exhibited high penicillin resistance (CMI $\geq 4 \mathrm{mg} / \mathrm{L})$, only 30 harbored the cep $A$ gene (Figures 1 and 2). 


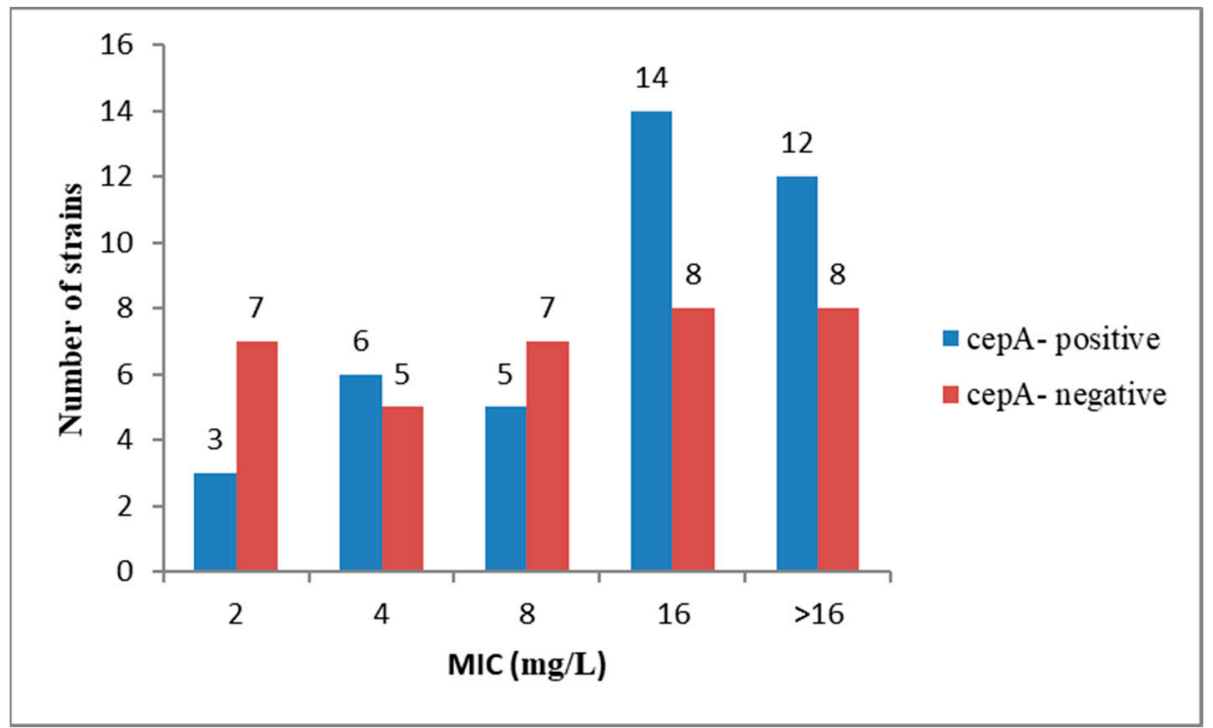

Figure 1. The presence of gene $\operatorname{cep} A$ was not correlated with ampicillin minimum inhibitory concentration (MIC) values.

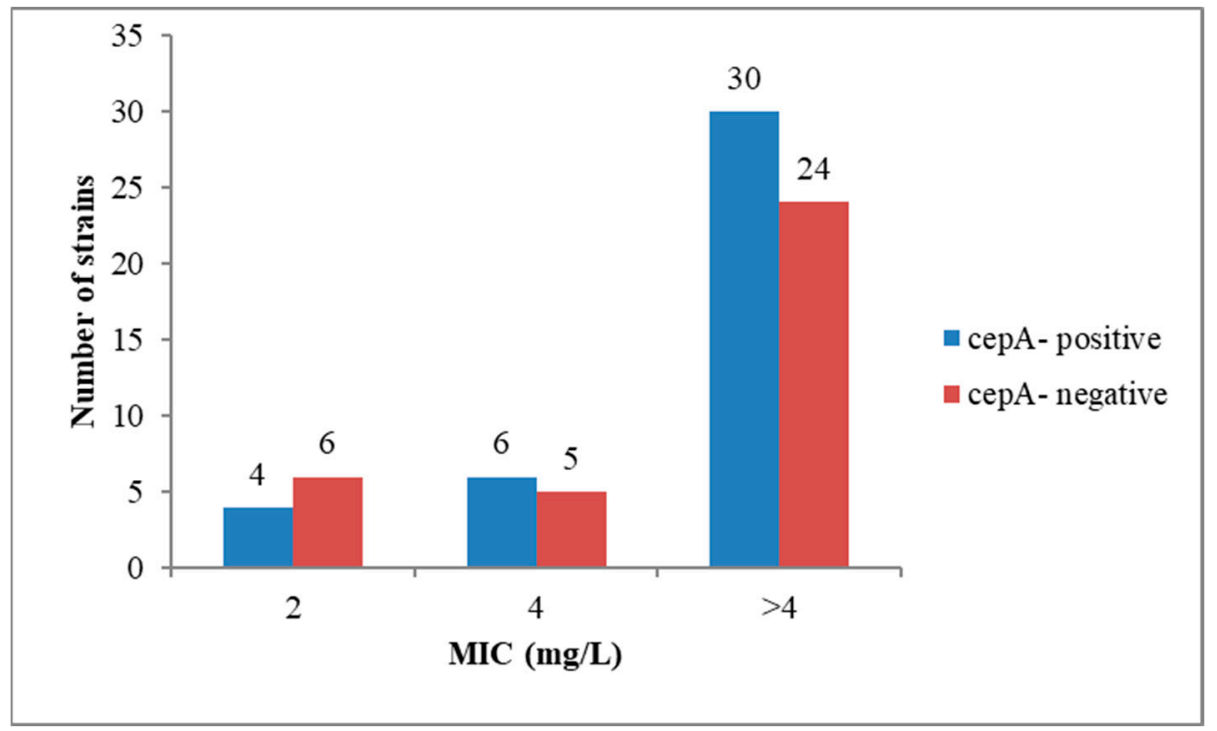

Figure 2. The presence of gene cepA was not correlated with penicillin MIC values.

The lack of correlation between the presence of серA gene and the MIC for AMP and PEN is suggesting the presence of other mechanisms of $\beta$-lactam resistance, such as mutations in the penicillin binding proteins (PBP) genes [8] or the presence of efflux pumps [9].

Of the 75 Bacteroides investigated strains, $16(21.9 \%)$ were CLI resistant (MIC $0.25 \geq 8 \mathrm{mg} / \mathrm{L}$ ) and, in most cases, the resistant strains were positive for the ermF gene (18.6\%) (Tables 3 and 4). Several authors have demonstrated also the association between the presence of the ermF gene and the clindamycin resistance $[10,11]$. 
Table 3. The prevalence of the antibiotic resistance and virulence genes in the analyzed Bacteroides strains.

\begin{tabular}{|c|c|c|c|c|c|c|c|}
\hline \multirow{3}{*}{ Species } & \multicolumn{7}{|c|}{ Gene } \\
\hline & \multicolumn{7}{|c|}{ (no.)\% } \\
\hline & серA & erm $F$ & tet $Q$ & $b f t-1$ & sod & katB & $f t n$ \\
\hline B. fragilis (26) & $17(65.3)$ & $4(15.3)$ & $26(100)$ & $15(57.6)$ & $9(34.6)$ & $7(26.9)$ & $7(30.4)$ \\
\hline Peritoneal liquid & $10(32)$ & $1(3.2)$ & $12(38.7)$ & $6(19.3)$ & $6(19.3)$ & $2(6.4)$ & $2(6.4)$ \\
\hline Intra-abdominal abscess & $1(33.3)$ & $1(33.3)$ & $3(100)$ & $2(66.6)$ & 0 & $2(66.6)$ & $2(66.6)$ \\
\hline Appendicular tissue & $2(11.1)$ & 0 & $3(16.6)$ & $2(11.1)$ & $1(5.5)$ & $1(5.5)$ & 0 \\
\hline Gallbladder secretion & $3(37.5)$ & 0 & $3(37.5)$ & $2(25)$ & $1(12.5)$ & 0 & 0 \\
\hline Ascites fluid & $1(11.1)$ & $2(22.2)$ & $4(44.4)$ & $3(33.3)$ & $1(11.1)$ & $2(22.2)$ & $2(22.2)$ \\
\hline Perforated ulcer-biopsy tissue & 0 & 0 & $1(25)$ & 0 & 0 & 0 & $1(25)$ \\
\hline B. vulgatus (16) & $10(62.5)$ & $4(25)$ & $15(93.7)$ & $0(0)$ & $2(12.5)$ & $0(0)$ & $0(0)$ \\
\hline Peritoneal liquid & $3(9.6)$ & $1(3.2)$ & $5(16.1)$ & 0 & $2(6.4)$ & 0 & 0 \\
\hline Intra-abdominal abscess & 0 & 0 & 0 & 0 & 0 & 0 & 0 \\
\hline Appendicular tissue & $3(16.6)$ & 0 & $3(16.6)$ & 0 & 0 & 0 & 0 \\
\hline Gallbladder secretion & $2(25)$ & $3(37.5)$ & $4(50)$ & 0 & 0 & 0 & 0 \\
\hline Ascites fluid & $1(11.1)$ & 0 & $1(11.1)$ & 0 & 0 & 0 & 0 \\
\hline Perforated ulcer-biopsy tissue & $1(25)$ & 0 & $2(25)$ & 0 & 0 & 0 & 0 \\
\hline B. uniformis (12) & $6(50)$ & $1(8.3)$ & $12(100)$ & $0(0)$ & $2(16.6)$ & $0(0)$ & $3(25)$ \\
\hline Peritoneal liquid & 0 & 0 & $3(9.6)$ & 0 & 0 & 0 & $1(3.2)$ \\
\hline Intra-abdominal abscess & 0 & 0 & 0 & 0 & 0 & 0 & 0 \\
\hline Appendicular tissue & $2(11.1)$ & $1(5.5)$ & $5(27.7)$ & 0 & 0 & 0 & $2(11.1)$ \\
\hline Gallbladder secretion & $1(12.5)$ & 0 & $1(12.5)$ & 0 & 0 & 0 & 0 \\
\hline Ascites fluid & $1(11.1)$ & 0 & $2(22.2)$ & 0 & $2(22.2)$ & 0 & 0 \\
\hline Perforated ulcer-biopsy tissue & $2(25)$ & 0 & $1(25)$ & 0 & 0 & 0 & 0 \\
\hline B. ovatus (7) & $1(14.2)$ & $1(14.2)$ & 7 (100) & $0(0)$ & $1(14.2)$ & $0(0)$ & $2(28.5)$ \\
\hline Peritoneal liquid & $1(3.2)$ & $1(3.2)$ & $4(13)$ & 0 & 0 & 0 & $2(6.4)$ \\
\hline Intra-abdominal abscess & 0 & 0 & 0 & 0 & 0 & 0 & 0 \\
\hline Appendicular tissue & 0 & 0 & $3(16.6)$ & 0 & $1(5.5)$ & 0 & 0 \\
\hline Gallbladder secretion & 0 & 0 & 0 & 0 & 0 & 0 & 0 \\
\hline Ascites fluid & 0 & 0 & 0 & 0 & 0 & 0 & 0 \\
\hline Perforated ulcer-biopsy tissue & 0 & 0 & 0 & 0 & 0 & 0 & 0 \\
\hline B. thetaiotaomicron (8) & $4(50)$ & $3(37.5)$ & $8(100)$ & $0(0)$ & $5(62.8)$ & $1(12.5)$ & 1 (12.5) \\
\hline Peritoneal liquid & $2(6.4)$ & $2(6.4)$ & $3(9.6)$ & 0 & $2(6.4)$ & 0 & 0 \\
\hline Intra-abdominal abscess & 0 & 0 & 0 & 0 & 0 & 0 & 0 \\
\hline Appendicular tissue & $2(11.1)$ & $1(5.5)$ & $4(22.2)$ & 0 & $2(11.1)$ & $1(5.5)$ & $1(5.5)$ \\
\hline Gallbladder secretion & 0 & 0 & 0 & 0 & 0 & 0 & 0 \\
\hline Ascites fluid & 0 & 0 & $1(11.1)$ & 0 & $1(11.1)$ & 0 & 0 \\
\hline Perforated ulcer-biopsy tissue & 0 & 0 & 0 & 0 & 0 & 0 & 0 \\
\hline B. caccae (1) & $1(100)$ & $0(0)$ & $1(100)$ & $0(0)$ & $1(100)$ & $0(0)$ & $0(0)$ \\
\hline Peritoneal liquid & 0 & 0 & 0 & 0 & 0 & 0 & 0 \\
\hline Intra-abdominal abscess & 0 & 0 & 0 & 0 & 0 & 0 & 0 \\
\hline Appendicular tissue & 0 & 0 & 0 & 0 & 0 & 0 & 0 \\
\hline Gallbladder secretion & 0 & 0 & 0 & 0 & 0 & 0 & 0 \\
\hline Ascites fluid & $1(11.1)$ & 0 & $1(11.1)$ & 0 & $1(11.1)$ & 0 & 0 \\
\hline Perforated ulcer-biopsy tissue & 0 & 0 & 0 & 0 & 0 & 0 & 0 \\
\hline
\end{tabular}


Table 3. Cont.

\begin{tabular}{|c|c|c|c|c|c|c|c|}
\hline \multirow{3}{*}{ Species } & \multicolumn{7}{|c|}{ Gene } \\
\hline & \multicolumn{7}{|c|}{ (no.) \% } \\
\hline & $\operatorname{cep} A$ & erm $F$ & tet $Q$ & $b f t-1$ & sod & katB & $f t n$ \\
\hline B. stercoris (5) & $1(20)$ & $1(20)$ & $5(100)$ & $0(0)$ & $0(0)$ & $0(0)$ & $0(0)$ \\
\hline Peritoneal liquid & $1(3.2)$ & $1(3.2)$ & $4(13)$ & 0 & 0 & 0 & 0 \\
\hline Intra-abdominal abscess & 0 & 0 & 0 & 0 & 0 & 0 & 0 \\
\hline Appendicular tissue & 0 & 0 & 0 & 0 & 0 & 0 & 0 \\
\hline Gallbladder secretion & 0 & 0 & 0 & 0 & 0 & 0 & 0 \\
\hline Ascites fluid & 0 & 0 & 0 & 0 & 0 & 0 & 0 \\
\hline Perforated ulcer-biopsy tissue & 0 & 0 & 0 & 0 & 0 & 0 & 0 \\
\hline Total (no.)\% & $40(53.3)$ & 14 (18.6) & 74 (98.6) & 15 (57.6) & $20(26.6)$ & $8(10.6)$ & 13 (17.3) \\
\hline
\end{tabular}

All strains were TET resistant (MIC $8 \geq 8 \mathrm{mg} / \mathrm{L}$ ) and, for the great majority of the investigated strains $(98.6 \%)$, the resistance could be correlated with the presence of the tet $Q$ gene (Tables 3 and 4 ). This correlation was also reported in other studies by Meggersee and Abratt [12] and Szekely et al. [13].

\subsection{Prevalence of Virulence Markers (VM) among Bacteroides spp.}

Of the 75 investigated Bacteroides strains, 20 (26.6\%) harbored the superoxide dismutase encoding gene (sod) involved in the pathogenicity of anaerobic bacteria, through its ability to neutralize the toxic levels of reactive oxygen species generated by the host [14]. A number of 13 (17.3\%) Bacteroides strains were positive for the ferritin gene $(f t n)$, involved in iron acquisition, and $8(10.6 \%)$ were positive for the $k a t B$ gene (catalase encoding gene, acting similarly with sod for decreasing the susceptibility of anaerobic bacteria to reactive oxygen species). The bft positive strains originated in the abdominal abscess and ascites fluid, followed by gallbladder and peritoneal liquid samples (Table 3).

Regarding the distribution of the sod gene by isolation sources, the gene was present mainly in the ascites fluid, peritoneal liquid and appendicular tissue samples. The majority of strains positive for the $f t n$ gene were isolated from intra-abdominal abscesses (67\%), whereas none of the strains from gallbladder harbored this gene. No strain isolated from abdominal abscess and perforated ulcer was positive for the sod gene.

Out of the total of 26 B. fragilis, 15 (57.6\%) harbored the enterotoxin encoding gene (bft) (Table 3). B. thetaiotaomicron showed the highest percentage of sod $(62.8 \%)$, followed by B. fragilis (34.6\%), B. ovatus $(14.2 \%)$, B. uniformis $(16.6 \%)$ and B. vulgatus $(12.5 \%)$. The katB gene was mostly identified in $B$. fragilis strains, which suggests the great survival ability of this species in the presence of oxygen.

\section{Discussion}

Our results in antibiotic resistance profiles are in accordance with Sarvari et al. [15], who recently reported a high level of resistance to AMP and TET in Bacteroides hospital-acquired strains, moderate level of resistance to CLI and susceptibility to MTR, AMC and CHL. Moreover, Javerica et.al. [16] revealed also a high level of resistance to PEN in Bacteroides hospital-acquired strains.

Concerning the correlation between the level of resistance and the clinical origin of the Bacteroides spp., our results show that the gallbladder isolates harbored the highest number of antibiotic resistance genes, namely tet $Q(100 \%)$, cep $A(75 \%)$ and ermF (38\%); while the strains isolated from perforated ulcers were the least resistant, presenting a lower frequency of tet $Q(75 \%)$ and cep $A$ genes $(50 \%)$ (Table 3$)$.

The bft positive strains originated in the abdominal abscess and ascites fluid, followed by gallbladder and peritoneal liquid samples, of which is different from other studies, where only $7.8 \%$ 
from peritoneal liquid strains were $b f t$ positive, a higher percentage of positivity was recorded for gallbladder strains (33.3\%), and similar rates were reported for the appendix isolates $(15.6 \%$ harbored $b f t-1$ gene) [17]. In our study of $26 \mathrm{~B}$. fragilis, 15 (57.6\%) harbored the enterotoxin encoding gene $(b f t)$. This positivity rate is higher than that reported in other studies (i.e., 13\% [18], 18.46\% [19] or $14.4 \%$ ) [20]. When comparing these rates, it must be taken into account that the number of $B$. fragilis strains was lower in our study (26), compared to the cited ones (72/65), and the type of the analyzed samples and pathology was different (in our case, the 26 strains were isolated from patients with intra-abdominal infections).

Table 4. Oligonucleotide primers used for the detection of virulence and resistance genes.

\begin{tabular}{|c|c|c|c|}
\hline Gene & Primer & Size & Ref. \\
\hline$b f t-1$ & $\begin{array}{l}\text { 5-GAGCCGAAGACGGTGTATGTGATTTGT-3 } \\
\text { 5-TGCTCAGCGCCCAGTATATGACCTAGT-3 }\end{array}$ & $500 \mathrm{bp}$ & [21] \\
\hline katB & $\begin{array}{l}\text { 5-GTAGCAGGAGAACGCGGAGCTGCT-3 } \\
\text { 5-GTTCATCCGCAGGCATCAGTCGGA-3 }\end{array}$ & $170 \mathrm{bp}$ & GenBank \\
\hline sod & $\begin{array}{l}\text { 5-ACAATGCGCTGGAACCTGTA-3 } \\
\text { 5-TTTCGAAGGTTTCGGAGCGA-3 }\end{array}$ & $230 \mathrm{bp}$ & GenBank \\
\hline$f t n$ & $\begin{array}{l}\text { 5-ACG TTTCAGCGGTTTTGCAC-3 } \\
\text { 5-CGTTCGTGCTCAAAGACGTG-3 }\end{array}$ & $183 \mathrm{bp}$ & GenBank \\
\hline серA & $\begin{array}{l}\text { 5-CGCAATGCCAAAGGACAACA-3 } \\
\text { 5-ACGATACGTGAGATGTCCGC-3 }\end{array}$ & $779 \mathrm{bp}$ & GenBank \\
\hline tet $Q$ & $\begin{array}{l}\text { 5-CTGTTTGCCAGTGGAGCAAC-3 } \\
\text { 5-AGCAACTTTGTCTGCGCTTG-3 }\end{array}$ & $460 \mathrm{bp}$ & GenBank \\
\hline$c f x A$ & $\begin{array}{l}5 \text {-GCTCAAACAGATAGTTTTAT-3 } \\
5 \text {-GAGCTCACAATGATGTTGCC-3 }\end{array}$ & 802 bp & [22] \\
\hline erm F & $\begin{array}{l}\text { 5-AGGTGCAGGGAAAGGTCATT-3 } \\
\text { 5-ACCTCTGCCATTAACAGCAAT-3 }\end{array}$ & $446 \mathrm{bp}$ & GenBank \\
\hline
\end{tabular}

\section{Materials and Methods}

\subsection{Anaerobic Bacterial Strains Isolation and Identification}

The study included 74 men (37.3\%) and 124 women (62.6\%) with the mean age of 55 years old, from which different clinical samples were taken intra-operatory and sent for microbiological analyses Synevo - Medicover Central Reference Laboratory, from Bucharest, Romania. The anaerobic strains were recovered following the cultivation of clinical samples in anaerobic conditions on anaerobic agar medium (Anaerobic Blood Agar, Phenylethyl alcohol agar and Schaedler Agar- Oxoid, Ireland, UK) and incubation at $37^{\circ} \mathrm{C}$ for 2-7 days in GasPak pouch system (Becton Dickinson Microbiology System, Shannon Industrial Estate Shannon, County Clare, Ireland).

The strains identification was performed using matrix-assisted laser desorption and ionization time of flight mass spectrometry (MALDI-TOF) on the Byotyper platform (Bruker Daltonics, Bremen, Germany). The isolated strains were stored in BHI broth (brain heart infusion) with $20 \%$ glycerol at $-80^{\circ} \mathrm{C}$. From the total number of isolated strains, a subset of 75 Bacteroides spp. were selected and further investigated for antibiotic resistance and virulence features, at phenotypic and genetic levels.

\subsection{Antibiotic Susceptibility Profiles}

The antimicrobial susceptibility testing was performed using the microdilution method (Sensititre Anaerobe MIC Plate, TREK Diagnostic Systems, UK) according to the CLSI 2019 and EUCAST 2019 guidelines. Antibiotic susceptibility was tested for ampicillin-sulbactam (AMS), amoxicillin-clavulanic acid (AMC), cefotetan (CEF), penicillin (PEN), imipenem (IMP), meropenem (MEM), clindamycin (CLI), cefoxitin (FOX), metronidazole (MTR), chloramphenicol (CHL), ampicillin (AMP), tetracycline (AMP) 
and piperacillin-tazobactam (PIP-TZP) for all Bacteroides strains. The quality control strains used was Bacteroides fragilis ATCC 25285. For $\beta$-lactamase production, a chromogenic cephalosporin (OXOID, Basingstoke, Hampshire, UK) test was used.

\subsection{Detection of the Antibiotic Resistance and Virulence Markers}

The genetic support of antibiotic resistance (cepA, $c f x$, tet $Q$ and erm $F)$ and virulence (bft-1, katB, sod and $f t n$ genes) was investigated by simplex and multiplex PCRs. Bacterial cells were resuspended in $20 \mu \mathrm{L}$ solution $0.05 \mathrm{NaOH}$ and $0.25 \%$ sodium dodecyl sulphate (SDS) and incubated at $95{ }^{\circ} \mathrm{C}$ for $15 \mathrm{~min}$. Next, $180 \mu \mathrm{L}$ TE (Tris EDTA) was added, followed by a 3 min centrifugation at 13,000 rpm. The supernatants were stored at $-20^{\circ} \mathrm{C}$. For PCR reactions, we used the primers described in Table 4 .

The PCR reactions were performed using $2 \times$ PCR Master Mix (Dream Taq Green, Thermo Scientific, Waltham, Massachusetts, USA) in a final volume $20 \mu \mathrm{L}$. The amplicons were visualized by electrophoresis in $1 \%$ agarose gel, stained with ethidium bromide $(10 \mu \mathrm{g} / \mathrm{mL})$ and identified using molecular weight specific markers (100 bp, Thermo Scientific).

\section{Conclusions}

This study is among the few studies performed in Romania investigating the antibiotic resistance profiles as well as the genetic support of antibiotic resistance, and the first reporting on the virulence determinants of anaerobic bacteria isolated from intra-abdominal infections [23-26]. The bacterial etiology of intra-abdominal infections has a broad spectrum of bacterial species belonging to endogenous microbiota (Fam. Enterobacteriaceae, Clostridium spp. and Bacteroides spp.), with an incidence of anaerobic species of $40.3 \%$. The species of Bacteroides genus dominated the anaerobic etiology, representing $49.6 \%$ of the total of 151 isolated anaerobic strains, followed by Clostridium sp. strains (20.5\%). The Bacteroides strains were totally resistant to ampicillin, penicillin and tetracycline and exhibited variable resistance rates to clindamycin $(21.9 \%)$, cefotetan $(10.9 \%)$ and cefoxitin $(1.3 \%)$. The isolated strains preserved entirely their susceptibility to metronidazole, amoxicillin/clavulanate, ampicillin with sulbactam, imipenem, meropenem, chloramphenicol and piperacillin with tazobactam. However, the frequency of antibiotics resistance/virulence determinants among analyzed strains could be higher if we take into account the entire anaerobic bacteria population of the sample. Due to the methodological restrictions assigned to the antibiotic susceptibility test (AST), where only a few colonies are picked up for AST, the result highlights only a small portion of the resistance reservoir. Studies show that when biological samples are incubated in the presence of different antibiotics, a surprising spectrum of resistant cells is revealed. This can be solved by changing the AST approach (i.e., replacing the selection of a few of colonies with a population-level approach), thus analyzing all bacterial population belonging to a clinical sample. This can be achieved by using new-generation PCR approaches which can measure in $\sim 2-4 \mathrm{~h}$ the response of the entire bacterial population of a sample to different antibiotics [27-29]. The Bacteroides spp. exhibited different virulence genes profiles, depending on the isolation source, with the abdominal abscesses and ascites fluid isolates being the most virulent.

There is a paucity of scientific information regarding the genetic and molecular aspects of virulence factors during anaerobic intra-abdominal infections, thus our results, obtained through the analysis of a significant number of Bacteroides spp., could shed light on the virulence potential and mechanisms by which anaerobic bacteria can cause endogenous infections.

Supplementary Materials: The following are available online at http://www.mdpi.com/2076-0817/9/11/940/s1, Table S1: The antibiotic resistance profiles of the analyzed Bacteroides strains according CLSI 2019 (S = Susceptible; $\mathrm{I}=$ Intermediate; $\mathrm{R}=$ Resistant; $\mathrm{R}(\%)=$ Resistance $(\%)$; Table S2 The antibiotic resistance profiles of the analyzed Bacteroides strains according EUCAST 2019 (S = Susceptible; I = Intermediate; R = Resistant; R(\%) = Resistance $(\%)$.

Author Contributions: Conceptualization, G.M. and M.C.C.; methodology, G.R.P., I.G., G.G.P.; formal analysis, V.C.; investigation, M.P., L.M.; writing—original draft preparation, G.R.P., I.G., G.G.P.; writing—review and editing, E.B., M.C.C.; supervision, G.M.; funding acquisition, M.C.C. All authors have read and agreed to the published version of the manuscript. Please turn to the CRediT taxonomy for the term explanation. Authorship must be limited to those who have contributed substantially to the work reported. 
Funding: This research was funded by the Research Projects PN-III-P4-ID-PCCF-2016-0114 and FDI-2020-0834 awarded to M.C.C.

Conflicts of Interest: The authors declare no conflict of interest.

\section{References}

1. Brook, I. Indigenous Microbial Flora of Humans, Surgica Infections Diseases, 3rd ed.; Appleton and Lange: Norwalk, CT, USA, 1995; pp. 37-46.

2. Jorgensen, J.H.; Carrol, K.C.; Funke, G.; Pfaller, M.A. Manual of Clinical Microbiology; ASM Press: Washington, DC, USA, 2015; Volume 1, Chapter 54; pp. 967-985.

3. Noor, A.; Khetarpal, S. Anaerobic Infections. In StatPearls; StatPearls Publishing: Treasure Island, FL, USA, 2020. Available online: https://www.ncbi.nlm.nih.gov/books/NBK482349/ (accessed on 20 August 2020).

4. Aldridge, K.E.; Ashcraft, D.; Cambre, K.; Pierson, C.L.; Jenkins, S.G.; Rosenblatt, J.E. Multicenter Survey of the Changing In Vitro Antimicrobial Susceptibilities of Clinical Isolates of Bacteroides fragilis Group, Prevotella, Fusobacterium, Porphyromonas, and Peptostreptococcus Species. Antimicrob. Agents Chemother. 2001, 45, 1238-1243. [CrossRef]

5. Nagy, E.; Urbán, E.; Nord, C.E.; ESCMID Study Group on Antimicrobial Resistance in Anaerobic Bacteria. Antimicrobial susceptibility of Bacteroides fragilis group isolates in Europe: 20 years of experience. Clin. Microbiol. Infect. 2011, 17, 371-379. [CrossRef]

6. Karlowsky, J.A.; Walkty, A.J.; Adam, H.J.; Baxter, M.R.; Hoban, D.J.; Zhanel, G.G. Prevalence of Antimicrobial Resistance among Clinical Isolates of Bacteroides fragilis Group in Canada in 2010-2011: CANWARD Surveillance Study. Antimicrob. Agents Chemother. 2012, 56, 1247-1252. [CrossRef]

7. Eitel, Z.; Sóki, J.; Urbán, E.; Nagy, E. The prevalence of antibiotic resistance genes in Bacteroides fragilis group strains isolated in different European countries. Anaerobe 2013, 21, 43-49. [CrossRef]

8. Píriz, S.; Vadillo, S.; Quesada, A.; Criado, J.; Cerrato, R.; Ayala, J.A. Relationship between penicillin-binding protein patterns and $\beta$-lactamases in clinical isolates of Bacteroides fragilis with different susceptibility to $\beta$-lactam antibiotics. J. Med. Microbiol. 2004, 53, 213-221. [CrossRef]

9. Ghotaslou, R.; Yekani, M.; Memar, M.Y. The role of efflux pumps in Bacteroides fragilis resistance to antibiotics. Microbiol. Res. 2018, 210, 1-5. [CrossRef]

10. Kierzkowska, M.; Majewska, A.; Szymanek-Majchrzak, K.; Sawicka-Grzelak, A.; Mlynarczyk, A.; Młynarczyk, G. In vitro effect of clindamycin against Bacteroides and Parabacteroides isolates in Poland. J. Glob. Antimicrob. Resist. 2018, 13, 49-52. [CrossRef]

11. Johnsen, B.O.; Handal, N.; Meisal, R.; Bjørnholt, J.V.; Gaustad, P.; Leegaard, T.M. erm gene distribution among Norwegian Bacteroides isolates and evaluation of phenotypic tests to detect inducible clindamycin resistance in Bacteroides species. Anaerobe 2017, 47, 226-232. [CrossRef]

12. Meggersee, R.; Abratt, V.R. The occurrence of antibiotic resistance genes in drug resistant Bacteroides fragilis isolates from Groote Schuur Hospital, South Africa. Anaerobe 2015, 32, 1-6. [CrossRef]

13. Székely, E.; Eitel, Z.; Molnár, S.; Szász, I. Éva; Bilca, D.; Sóki, J. Analysis of Romanian Bacteroides isolates for antibiotic resistance levels and the corresponding antibiotic resistance genes. Anaerobe 2015, 31, 11-14. [CrossRef]

14. Cox, G.M.; Harrison, T.S.; McDade, H.C.; Taborda, C.P.; Heinrich, G.; Casadevall, A.; Perfect, J.R. Superoxide Dismutase Influences the Virulence of Cryptococcus neoformans by Affecting Growth within Macrophages. Infect. Immun. 2003, 71, 173-180. [CrossRef] [PubMed]

15. Sarvari, K.P.; Soki, J.; Kristof, K.; Juhasz, E.; Miszti, C.; Latkoczy, K.; Melegh, S.Z.; Urban, E. A multicenter survey of the antibiotic susceptibility of clinical Bacteroides species from Hungary. Infect. Dis. 2018, 50, 372-380. [CrossRef] [PubMed]

16. Jeverica, S.; Kolenc, U.; Mueller-Premru, M.; Papst, L. Evaluation of the routine antimicrobial susceptibility testing results of clinically significant anaerobic bacteria in a Slovenian tertiary-care hospital in 2015. Anaerobe 2017, 47, 64-69. [CrossRef] [PubMed]

17. Avila-Campos, M.J.; Liu, C.; Song, Y.; Rowlinson, M.-C.; Finegold, S.M. Determination of bft Gene Subtypes in Bacteroides fragilis Clinical Isolates. J. Clin. Microbiol. 2007, 45, 1336-1338. [CrossRef] [PubMed]

18. Sarvari, K.P.; Sóki, J.; Iván, M.; Miszti, C.; Latkóczy, K.; Melegh, S.; Urbán, E. Detection of enterotoxin and protease genes among Hungarian clinical Bacteroides fragilis isolates. Anaerobe 2017, 48, 98-102. [CrossRef] 
19. Łuczak, M.; Obuch-Woszczatyński, P.; Pituch, H.; Leszczyński, P.; Martirosian, G.; Patrick, S.; Poxton, I.; Wintermans, R.G.; Dubreuil, L.; Meisel-Mikołajczyk, F. Search for enterotoxin gene in Bacteroides fragilis strains isolated from clinical specimens in Poland, Great Britain, The Netherlands and France. Med. Sci. Monit. 2001, 7, 222-225.

20. Kierzkowska, M.; Majewska, A.; Szymanek-Majchrzak, K.; Sawicka-Grzelak, A.; Mlynarczyk, A.; Mlynarczyk, G. The presence of antibiotic resistance genes and bft genes as well as antibiotic susceptibility testing of Bacteroides fragilis strains isolated from inpatients of the Infant Jesus Teaching Hospital, Warsaw during 2007-2012. Anaerobe 2019, 56, 109-115. [CrossRef]

21. Toprak, N.U.; Yagci, A.; Gulluoglu, B.M.; Akin, M.L.; Demirkalem, P.; Celenk, T.; Soyletir, G. A possible role of Bacteroides fragilis enterotoxin in the aetiology of colorectal cancer. Clin. Microbiol. Infect. 2006, 12, 782-786. [CrossRef]

22. Parker, A.C.; Smith, C.J. Genetic and biochemical analysis of a novel Ambler class A beta-lactamase responsible for cefoxitin resistance in Bacteroides species. Antimicrob. Agents Chemother. 1993, 37, 1028-1036. [CrossRef]

23. Oancea, S.; Stoia, M. Antibiotic resistance of bacterial pathogens: The magnitude of the problem from two perspectives-Romanian and worldwide. Rom. Biotechnol. Lett. 2010, 15, 5519e29.

24. Almahdawy, O.T.; Pricop, R.; Sadik, O.; Najee, H.; Pircalabioru, G.G.; Marutescu, L.; Barbu, I.C.; Banu, O.; Cristea, V.; Grigore, R.; et al. Description of vancomycin resistance genes in Enterococcus sp. clinical strains isolated from Bucharest, Romania. Rom. Biotechnol. Lett. 2019, 24, 395-399. [CrossRef]

25. Iancu, A.V.; Chifiriuc, M.C.; Tutunaru, D.; Arbune, M.; Gurău, G.; Coman, G.; Lazăr, V. Etiological investigation and antibiotic resistance profiles encountered in systemic bacterial infections. Biointerface Res. Appl. Chem. 2013, 3, 4 .

26. Ducu, R.; Gheorghe, I.; Chifiriuc, M.C.; Mihăescu, G.; Sârbu, I. Prevalence of vancomycin resistance phenotypes among enterococcus species isolated from clinical samples in a romanian hospital. Biointerface Res. Appl. Chem. 2019, 9, 4699-4704.

27. Brukner, I.; Oughton, M.T. A Fundamental Change in Antibiotic Susceptibility Testing Would Better Prevent Therapeutic Failure: From Individual to Population-Based Analysis. Front. Microbiol. 2020, 11, 1-4. [CrossRef] [PubMed]

28. Maxson, T.; Blancett, C.D.; Graham, A.S.; Stefan, C.P.; Minogue, T.D. Rapid antibiotic susceptibility testing from blood culture bottles with species agnostic real-time polymerase chain reaction. PLoS ONE 2018, 13, e0209042. [CrossRef]

29. Rolain, J.M.; Mallet, M.N.; Fournier, P.E.; Raoult, D. Real-time PCR for universal antibiotic susceptibility testing. J. Antimicrob. Chemother. 2004, 54, 538-541. [CrossRef]

Publisher's Note: MDPI stays neutral with regard to jurisdictional claims in published maps and institutional affiliations.

(C) 2020 by the authors. Licensee MDPI, Basel, Switzerland. This article is an open access article distributed under the terms and conditions of the Creative Commons Attribution (CC BY) license (http://creativecommons.org/licenses/by/4.0/). 